\title{
A sigilografia portuguesa em tempos de Afonso Henriques
}

Maria do Rosário Barbosa Morujão

\section{(2) OpenEdition}

\section{Journals}

\section{Edição electrónica}

URL: http://journals.openedition.org/medievalista/744

DOI: 10.4000/medievalista.744

ISSN: 1646-740X

\section{Editora}

Instituto de Estudos Medievais - FCSH-UNL

Edição impressa

Data de publição: 1 Janeiro 2012

\section{Refêrencia eletrónica}

Maria do Rosário Barbosa Morujão, «A sigilografia portuguesa em tempos de Afonso Henriques »,

Medievalista [Online], 11 | 2012, posto online no dia 21 fevereiro 2014, consultado no dia 01 maio 2019 URL : http://journals.openedition.org/medievalista/744 ; DOI : 10.4000/medievalista.744

(C) IEM 


\section{Revista ISSN 1646-740X}

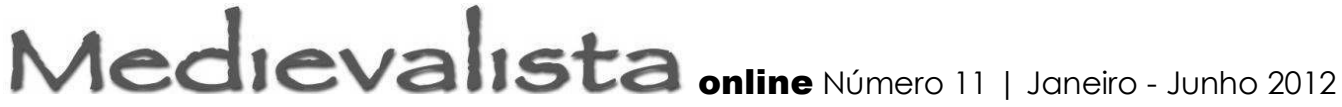

Título: A sigilografia portuguesa em tempos de Afonso Henriques.

Autor(es): Maria do Rosário Barbosa Morujão

Enquadramento Institucional: Faculdade de Letras da Universidade de Coimbra; Centro

de História da Sociedade e da Cultura - UC; Centro de Estudos de História Religiosa -

UCP

Contacto: rmorujao@gmail.com

Fonte: Medievalista [Em linha]. №11, (Janeiro 2012). Direc. José Mattoso. Lisboa: IEM.

Disponível em: http://www2.fcsh.unl.pt/iem/medievalista/

ISSN: 1646-740X

\section{Resumo}

Este artigo propõe-se estudar os primórdios da sigilografia portuguesa, coincidentes com o governo de D. Afonso Henriques. Nele se sintetiza o conhecimento que o actual estado da investigação nos permite ter a respeito do início do uso do selo em Portugal como forma de validação documental em chancelarias episcopais, monásticas e régia. É dada uma importância especial aos selos reais, propondo uma possível explicação para o carácter eminentemente heráldico que marcou desde sempre a sigilografia régia portuguesa, evidenciando a importância como guerreiro de D. Afonso Henriques, simbolizada no seu escudo, como um factor que deu legitimidade à sua condição régia e à independência de Portugal. As suas armas tornaram-se, elas próprias, o símbolo do novo rei e da dinastia a que ele deu origem, assim permanecendo presentes em todos os selos dos monarcas portugueses.

Palavras-chave: Afonso Henriques, sigilografia, selos régios, selos episcopais selos monásticos armas régias. 


\section{Abstract}

This article aims at studying the beginnings of the Portuguese sigillography, which coincide with the government of Afonso Henriques. It synthesizes the knowledge that the current state of research allows about the early use of the seal in Portugal as a form of validating documents from episcopal, monastic and royal chanceries. A special importance is given to the royal seals, exploring a possible explanation for the eminently heraldic character that always marked the royal Portuguese sigillography, pointing to the importance as a warrior of Afonso Henriques, symbolized by his shield of arms, as a factor that gave legitimacy to his kingship and the independence of Portugal. His heraldry became itself the symbol of the new king and of the dynasty he gave birth to, thus remaining in all the Portuguese monarchs seals.

Keywords: Afonso Henriques, sigillography, royal seals, episcopal seals, monastic seals, royal shields of arms. 


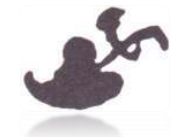

\section{A sigilografia portuguesa em tempos de Afonso Henriques $^{1}$}

\author{
Maria do Rosário Barbosa Morujão
}

No dealbar do século XII, os selos contavam já milénios de história, desde as civilizações mesopotâmicas que os inventaram como modo de fechar, identificar e validar objectos e documentos - três funções que mantêm até hoje, sendo a última, porém, a única que, de momento, nos interessa abordar ${ }^{2}$. Foram depois usados, para idênticos fins, por gregos e romanos, imperadores bizantinos e papas, tendo-se, por intermédio destes últimos, difundido por toda a cristandade medieval. A este extremo ocidental da Europa onde, há 900 anos, Afonso Henriques nasceu, chegaram precisamente durante o tempo da sua vida.

Antes da sua introdução entre nós, outras formas de validação eram já, naturalmente, utilizadas, e continuaram a sê-lo, em conjugação com a nova prática ${ }^{3}$. Todas elas, porém, tinham um grave inconveniente: eram fáceis de falsificar e imitar, sendo em contrapartida difícil verificar a autenticidade do documento após a morte dos que

\footnotetext{
${ }^{1}$ Este artigo tem como base a comunicação apresentada ao Congresso Internacional Afonso Henriques. 900 anos depois, organizado pela Câmara Municipal de Viseu e pelo Centro de Estudos Históricos da Universidade Nova de Lisboa, que teve lugar em Viseu entre 16 e 19 de Setembro de 2009. Foi, entretanto, devidamente actualizado e ampliado para publicação.

${ }^{2}$ Sobre a história dos selos desde o seu aparecimento, vejam-se as sínteses propostas por BAUTIER, Robert-Henri - Le cheminement du sceau et de la bulle des origines mésopotamiennes au XIII ${ }^{\mathrm{e}}$ siècle occidental. In BAUTIER, Robert-Henri - Chartes, sceaux et chancelleries. Études de Diplomatique et de Sigillographie médiévales. Vol. 1. Paris: École des Chartes, 1990, p. 123-166, e PASTOUREAU, Michel - Les sceaux. Turnhout: Brepols, 1981.

${ }^{3}$ Acerca dos processos de validação usados na documentação medieval portuguesa, vejam-se as seguintes obras: CUNHA, Maria Cristina Almeida e - A chancelaria arquiepiscopal de Braga (1071-1244). Noia: Toxosouto, 2005, p. 147-158; MORUJÃO, Maria do Rosário Barbosa - A Sé de Coimbra: a instituição e a chancelaria (1080-1318). Lisboa: FCG/FCT, 2010, p. 577-699; GOMES, Saul António - In limine conscriptionis. Documentos, chancelaria e cultura no mosteiro de Santa Cruz de Coimbra: séculos XII a XIV. Viseu: Palimage, 2007, p. 819-921.
} 
tinham participado na sua elaboração. Os selos, pelo contrário, ultrapassavam esses condicionalismos, podendo continuar, ao longo dos séculos, a testemunhar a genuinidade do acto escrito a que estavam apostos. Assim o reconheceu o papa Alexandre III, ao declarar que um documento deixaria de fazer fé uma vez desaparecidas as suas testemunhas, a menos que tivesse sido escrito por notário público ou que estivesse munido de selo ${ }^{4}$. Os notários públicos, com aptidão para escreverem documentos reconhecidos como autênticos em juízo, apenas viriam a existir em Portugal a partir do reinado de D. Afonso II $^{5}$. Já os selos, como dissemos, começaram a ser utilizados no tempo de D. Afonso Henriques, e, uma vez introduzidos no território portucalense, foram, lentamente, ganhando terreno, até se transformarem na principal forma de autenticação documental, alcançando uma absoluta primazia durante os séculos XIII e XIV face a todos os outros processos validatórios. Perderam importância nas centúrias subsequentes, mas, no entanto, não mais deixaram de existir, permanecendo em uso até aos nossos dias.

Note-se que os selos não valem nem interessam apenas como elementos que garantem a autenticidade de um acto escrito; são também, em si mesmos e de pleno direito, fontes históricas de primeira importância, testemunhos tão preciosos quanto modestos de tempos, não apenas medievais, mas também modernos e contemporâneos, permitindo múltiplas abordagens, não só do ponto de vista da Diplomática, mas ainda na sua qualidade de produtos obtidos por técnicas artesanais específicas, e no âmbito da história da arte e da simbologia, dado o seu importantíssimo valor iconográfico e emblemático ${ }^{6}$. Pequenos monumentos que têm estado, porém, demasiado sujeitos a um quase esquecimento, não se lhes conferindo, as mais das vezes, a devida importância, nem se acautelando devidamente a sua preservação ${ }^{7}$. E os selos são frágeis: soltam-se, partem-se, escamam, ficam delidos, gastos pelo uso, ou, literalmente, pulverizam-se;

\footnotetext{
${ }^{4}$ GOMES, S. A. - In limine..., p. 834.

5 Sobre a introdução do notariado público em Portugal, ver, em especial, a tese de doutoramento de NOGUEIRA, Bernardo de Sá - Tabelionado e instrumento público em Portugal. Génese e implantação (1212-1279). Lisboa: Imprensa Nacional Casa da Moeda, 2008.

${ }^{6}$ Cf. PASTOUREAU, M. - Les sceaux.

${ }^{7}$ Ver, quanto a esta problemática, GOMES, S. A. - In limine..., p. 913-915, e Introdução à sigilografia portuguesa. Guia de estudo. Coimbra: Faculdade de Letras, 2008, p. 77-79; MORUJÃO, M. R. - A Sé de Coimbra..., p. 635-636; MORUJÃO, M. R. - The seals from the fund of the Coimbra See Chapter at the Torre do Tombo National Archive. In Actas do Seminário Internacional "Preserving documents science and restoration" (em vias de publicação on-line).
} 
sofreram e sofrem maus-tratos, decorrentes não só da passagem dos séculos e de deficientes condições ambientais, mas também (e, talvez, sobretudo) da incúria humana, tanto passada como presente ${ }^{8}$.

Tentar reconstituir os primórdios da sigilografia portuguesa, como é nosso intento neste artigo, não é tarefa fácil, por vários motivos. Em primeiro lugar, por serem poucos os originais que subsistiram desses recuados tempos, havendo muitos documentos que só nos chegaram sob a forma de cópias, e sendo ainda menor o número daqueles que, tendo sido dotados de selos, os conservam até hoje ${ }^{9}$. Em segundo lugar, porque existem muito poucos estudos sigilográficos portugueses que nos permitam conhecer com exactidão os selos que lograram sobreviver ou de que há notícia ${ }^{10}$. Fazer a história da introdução dos selos entre nós é, por isso, um pouco como procurar construir um puzzle de que só restam algumas peças, demasiado poucas e quase sempre mutiladas.

Essas peças encontram-se, naturalmente, entre a documentação do século XII depositada nos nossos arquivos e bibliotecas, que é constituída, essencialmente, por actos de proveniência eclesiástica, tanto do clero secular como regular, ou produzidos na chancelaria régia. $\mathrm{O}$ que se apresenta de seguida não pretende ser mais do que uma síntese do que, no actual estado dos conhecimentos, se pode dizer relativamente ao início do uso do selo em cada um destes três universos documentais.

Parece não haver dúvidas de que a primazia na adopção das práticas sigilográficas no território português terá pertencido aos bispos, que tinham sido também os mais precoces nesse domínio em toda a Europa, logo a partir de meados do século $\mathrm{X}$, por influência da chancelaria do império bizantino ${ }^{11}$. Primeiro aderiram a eles os prelados

\footnotetext{
${ }^{8}$ Exemplos destas situações podem ser encontrados nos estudos citados anteriormente, assim como na obra que continua a ser a principal referência no campo da sigilografia portuguesa: TÁVORA, Luís Gonzaga de Lancastre e - O estudo da sigilografia medieval portuguesa. Lisboa: Instituto de Cultura e Língua Portuguesa, 1983.

${ }^{9}$ A este respeito, vejam-se os números avançados quanto a Santa Cruz por GOMES, S. A. - In limine..., p. 913-915 e no que toca à Sé de Coimbra por MORUJÃO, M. R. - A Sé de Coimbra ..., p. 635-636.

${ }^{10}$ Um elenco da principal bibliografia sobre sigilografia portuguesa encontra-se em GOMES, S. A. Introdução à sigilografia ..., p. 206-215.

${ }^{11}$ Veja-se BAUTIER, Robert-Henri - Apparition, diffusion et évolution typologique du sceau épiscopal au Moyen Âge. In HAIDACHER, Christoph; KÖFLER, Werner (eds.) - Die Diplomatik der Bischofsurkunde vor 1250. La Diplomatique épiscopale avant 1250. Innsbruck: Tiroler Landesarchiv, 1995, p. 225-241; RIESCO TERRERO, Angel - El sello episcopal hasta el Renacimiento. Valoración
} 
das dioceses da Renânia, depois os de todo o espaço germânico, assim como os da França e da Inglaterra, que já utilizavam o selo no século XI. A presença entre nós de bispos estrangeiros, ou em frequente contacto com outras terras, facilitou, decerto, a importação dessa prática ${ }^{12}$.

Seria esse o caso de D. Pedro Rabaldes, bispo do Porto de 1138 a $1145^{13}$, ao qual diz respeito a mais antiga referência a um selo episcopal, datada de 1144. O documento que autenticava, uma composição com a Ordem do Templo lavrada em Junho desse ano, só nos chegou através de cópia registada no Censual do Cabido dessa Sé ${ }^{14}$; não conhecemos, pois, este selo, mas apenas a notícia da sua existência. D. Pedro Rabaldes era filho do francês D. Rabaldo, um dos companheiros do conde D. Henrique, com ele vindo para a Península ${ }^{15}$; estaria em boas condições, portanto, para conhecer e adoptar as práticas sigilográficas que, em terras de Borgonha, já se tinham, então, implantado.

A segunda referência, do ano seguinte, é relativa ao arcebispo de Braga D. João Peculiar (1138-1175†), personagem bem conhecida da nossa história, como apoiante de D. Afonso Henriques e seu braço direito na prossecução de uma política defensora de um espaço eclesiástico portucalense dependente de uma autoridade religiosa portucalense também ${ }^{16}$. D. João, segundo tudo indica português de origem, deslocou-se a França

jurídico-diplomática y artística del mismo. In Actas del XV Congreso Internacional de las Ciencias Genealógica y Heráldica. Madrid, 19-25 septiembre 1982. Tomo 3. Madrid: Instituto Salazar y Castro, 1983, p. 365-389; HARVEY, P. D. A.; MCGUINESS, Andrew - A guide to British medieval seals. Londres: British Library / Public Record Office, 1996, p. 63-75; MORUJÃO, M. R. - Imagens de selos. Anotações de sigilografia pontifícia e episcopal. In Colecção Esfragística da Faculdade de Letras da Universidade de Coimbra. Catálogo da Exposição, Coimbra: Reitoria da Universidade, 2003, p. 61-70.

12 Sobre a origem dos bispos portugueses dessa época, vejam-se as seguintes obras que se dedicam ao estudo de diversas dioceses no período cronológico que nos interessa: BRANCO, Maria João Violante Reis, bispos e cabidos: a diocese de Lisboa durante o primeiro século da sua restauração. Lusitania Sacra, Lisboa. 10 (1998), p. 55-94; VILAR, Hermínia Vasconcelos - As dimensões de um poder. A diocese de Évora na Idade Média. Lisboa: Estampa, 1999; CUNHA, M. C. - A chancelaria arquiepiscopal de Braga...; MORUJÃO, M. R. - A Sé de Coimbra...; SILVA, Maria João Oliveira e - Scriptores et notatores. A produção documental da Sé do Porto (1113-1247). Porto: Fio da Palavra, 2008.

${ }^{13}$ Sobre D. Pedro Rabaldes como bispo do Porto, vid. SILVA, M. J. - Scriptores et notatores..., p. 26-27.

${ }^{14}$ Censual do Cabido da Sé do Porto: códice membranáceo existente na Biblioteca do Porto. Ed. João Grave. Porto: Imprensa Portuguesa, 1924, p. 353-354 e SILVA, M. J. - Scriptores et notatores ..., p. 128.

${ }^{15}$ Sobre a família de D. Pedro Rabaldes, vid. VENTURA, Leontina - O elemento franco na Coimbra do século XII: a família dos Rabaldes. Revista Portuguesa de História. Coimbra. 36: 1 (2002-2003), p. 89114.

${ }^{16}$ A seu respeito, vid. a breve síntese apresentada por COSTA, Avelino de Jesus da - D. João Peculiar, co-fundador do mosteiro de Santa Cruz de Coimbra, bispo do Porto e arcebispo de Braga. In Santa Cruz 
numerosas vezes, contactando com as novas realidades aí vigentes, nomeadamente com os movimentos reformadores da Igreja que então se desenvolviam, como os cónegos regrantes de Santo Agostinho e a reforma beneditina que deu origem à Ordem de Cister; esteve ligado, aliás, à introdução de ambas as obediências em Portugal ${ }^{17}$. Do seu selo também apenas nos chegou a notícia, em cópia do século XIV, que nos informa que autenticava um diploma de 1145, e que descreve este espécime sigilográfico como tendo gravado no campo uma imagem que parecia de uma águia (quedam figuram que aparebat aquila $)^{18}$, o que nos parece bastante inusitado como figuração para um selo episcopal, já que na maioria dos casos o motivo escolhido era a representação do próprio prelado $^{19}$. Poderá ter havido uma má interpretação da gravura por parte do tabelião que a viu, dois séculos volvidos após a sua execução? O mais importante, de momento, para a nossa pesquisa, é sabermos que D. João Peculiar fazia uso de um selo pendente em 1145, como arcebispo bracarense.

A notícia seguinte diz respeito a um hipotético selo do bispo de Lisboa D. Gilberto (1147-1163), aposto em diploma de 1159, pelo qual o prelado renunciava a certos direitos episcopais a favor dos Templários ${ }^{20}$. O documento sobreviveu até hoje, conservando apenas, porém, os furos de suspensão do selo. Como há muito alertou o

de Coimbra do século XI ao século XX. Estudos no IX centenário do nascimento de S. Teotónio. Coimbra: [s.n.], 1984, p. 59-83.

${ }^{17}$ Sobre a introdução dos cónegos regrantes, vid. MARTINS, Armando Alberto - O mosteiro de Santa Cruz de Coimbra na Idade Média, Lisboa: Centro de História da Universidade, 2003, p. 73-233 e GOMES, S. A. - In limine..., p. 105-159; relativamente às origens da Ordem cisterciense em Portugal, vid. MARQUES, Maria Alegria F. - A introdução da Ordem de Cister em Portugal. In MARQUES, Maria Alegria F. - Estudos sobre a Ordem de Cister em Portugal, Lisboa: Colibri, 1998, p. 29-73; MATTOSO, José - Cluny, crúzios e cistercienses na formação de Portugal. In MATTOSO, José Portugal medieval: novas interpretações. Rio de Mouro: Círculo de Leitores, 2002, p. 79-93; e TORRE RODRÍGUEZ, José Ignacio de la - Evolução histórica de Cister no Vale do Douro. In DIAS, Geraldo Coelho; DUARTE, Luís Miguel (coord.) - Cister no Vale do Douro. Porto: Edições Afrontamento, 1999, p. 69-116.

${ }^{18}$ Vid. CUNHA, M. C. - A chancelaria ..., p. 172, e COSTA, A. J. - Sigilografia. In SERRÃO, Joel (dir.) - Dicionário de História de Portugal. Vol. 5. Porto: Figueirinhas, [s.d.], p. 564. Sobre a importância das descrições de selos feitas a posteriori para o conhecimento de selos desaparecidos, vid. SANZ FUENTES, Maria Josefa - La recuperación de tipos sigilográficos y modos de aposición a traves de las formulas documentales. In Actas del Primer Coloquio de Sigilografía (Madrid, 2 al 4 de abril de 1987), Madrid: Direccion de los Archivos Estatales, 1990, p. 145-153.

19 Vid. BAUTIER, R.-H. - Apparition, diffusion..., p. 233-235; MORUJÃO, M. R. - Imagens de selos..., p. 66 e $A$ Sé de Coimbra..., p. 637-657.

${ }^{20}$ Este selo é referido por COSTA, A. J. - Sigilografia, p. 564, que, porém, não indica a cota do documento ao qual estaria apenso; pensamos tratar-se do diploma de Fevereiro de 1159 reproduzido em COSTA, A. J. - Álbum de Paleografia ..., doc. no 39 e MARQUES, José - A influência das bulas papais na documentação medieval portuguesa. Revista da Faculdade de Letras. História. Porto, 13 (1996), fig. 11. 
grande diplomatista português João Pedro Ribeiro ${ }^{21}$, que o viu, já desprovido de selo, nos inícios de Oitocentos, o documento não indica a selagem na corroboração e aparenta ter sido escrito na chancelaria régia, sendo, por isso, possível que tenha sido autenticado não com o selo do bispo, mas com o do monarca ${ }^{22}$. É provável, no entanto, que o selo pertencesse ao prelado: no final da década de 1150, um bispo inglês como D. Gilberto de Hastings (colocado na cátedra lisboeta por Afonso Henriques, na sequência do apoio que, com outros cruzados, dera à conquista da cidade ${ }^{23}$ ) estaria já familiarizado com a prática sigilográfica e não admira que tivesse e utilizasse o seu próprio selo ${ }^{24}$.

Na década seguinte, surgem-nos mais dois testemunhos de selos episcopais portugueses. O primeiro foi aposto na conhecida carta de liberdade outorgada pelo bispo de Coimbra D. Miguel Salomão (1162-1176) ao mosteiro de Santa Cruz, documento que fez correr muita tinta desde que foi lavrado, em Março de 1162, até aos dias de hoje $\mathrm{e}^{25}$. Por seu intermédio, o prelado, que fora antes cónego da canónica agostinha ${ }^{26}$, concedia aos crúzios a isenção da jurisdição episcopal à qual deveriam estar submetidos. Desde logo, o documento foi muito contestado, queixando-se os membros do cabido da catedral, que o subscreveram pelo seu próprio punho, de terem sido obrigados a fazê-lo sob ameaças. Disseram também (inclusive ao papa) que a carta teria sido subrepticiamente selada, tendo o capelão do bispo subtraído a sua matriz sigilar. Não vamos aqui discutir a problemática em torno desta concessão que, de facto, prejudicava os interesses da catedral, nem fazer a análise de todos os problemas que o documento, nas várias versões chegadas até nós, coloca ${ }^{27}$. Importa-nos reter, para o nosso propósito, que a sua selagem foi, certamente, feita a posteriori com os selos do bispo e do rei, o que significa que, em 1162 ou em data próxima, D. Miguel possuía, de facto, um selo. Se é aquele que o documento ainda ostenta, muito fragmentado e delido, é difícil de dizer (fig. 1). O seu

\footnotetext{
${ }^{21}$ RIBEIRO, João Pedro - Observações historicas e criticas para servirem de memorias ao systema da diplomatica portugueza, Lisboa: Tipografia da Academia Real das Ciências, 1798, p. 143.

${ }^{22}$ A semelhante conclusão chegámos nós, em $A$ Sé de Coimbra ..., p. 611, nota 954.

${ }^{23}$ A seu respeito, vid. o citado artigo de BRANCO, M. J. - Reis, bispos e cabidos..., p. 57-64.

${ }^{24}$ Sobre os selos episcopais em Inglaterra, vid. HARVEY, P. D. A.; MCGUINESS, A. - A guide ..., p. 6375.

${ }^{25}$ Sobre este documento e a sua selagem, vid. AZEVEDO, Rui de - Documentos falsos de Santa Cruz de Coimbra (séculos XII e XIII), Lisboa: José Fernandes Júnior, 1935; MARTINS, A. A. - O mosteiro de Santa Cruz..., p. 284-292; GOMES, S. A. - In limine..., p. 847-855; e MORUJÃO, M. R. - A Sé de Coimbra..., p. 109-110 e 611-612.

${ }^{26}$ Os dados biográficos conhecidos deste prelado podem ver-se em MORUJÃO, M. R. - A Sé de Coimbra..., p. 107-112.

${ }^{27}$ Remetemos a esse respeito para as obras citadas supra, nota 25.
} 
estado de conservação é tão mau que permite ver nele mais ou menos o que se quiser já houve quem vislumbrasse nestes relevos que restam as armas régias, que comprovariam ser o selo de Afonso Henriques; na nossa opinião, vê-se, na parte superior, a cabeça de um prelado mitrado e os seus ombros ${ }^{28}$. A este problema voltaremos mais adiante; por ora, o que interessa frisar é que D. Miguel Salomão, bispo de Coimbra, tinha selo por volta de 1162.

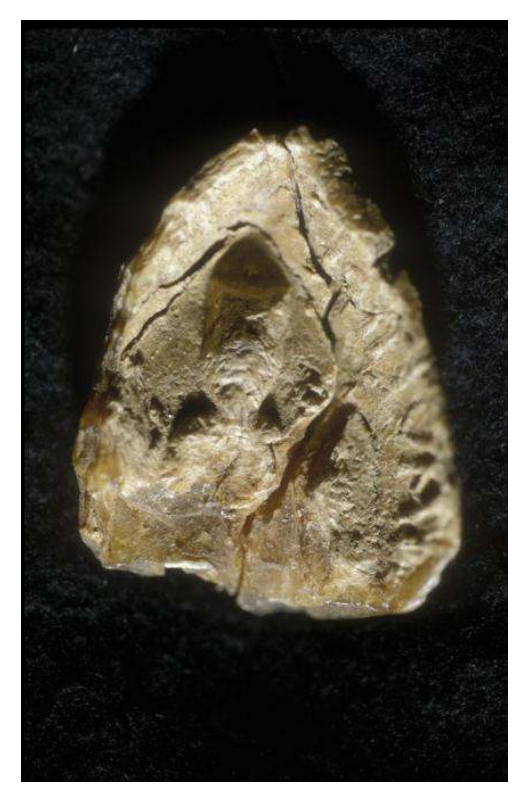

Fig. 1 - Selo de D. Miguel Salomão, bispo de Coimbra (?).

(ANTT, Mosteiro de Santa Cruz, DP, M. 5, no 18)

O segundo selo da década de 1160 a que existe menção pertencia ao bispo de Lamego D. Mendo (1147-1173) e tinha sido aposto em diploma de 1164, pelo qual o prelado renunciava aos direitos episcopais em favor do mosteiro de Salzedas ${ }^{29}$. Este documento foi analisado no cartório desse cenóbio no princípio do século XIX, por João Pedro Ribeiro, que descreveu o seu selo: era de cera, e tinha gravada a imagem de um bispo de

\footnotetext{
${ }^{28}$ A primeira leitura foi feita, inicialmente, por Saul Gomes, que no entanto veio a reconhecer como mais provável tratar-se do selo de D. Miguel (cf. In limine..., p. 849). Vid. os argumentos por nós usados em MORUJÃO, M. R. - A Sé de Coimbra..., p. 638.

${ }^{29}$ Sobre D. Mendo e a sua actuação à frente do recém-restaurado bispado de Lamego, nomeadamente a renúncia dos seus direitos episcopais a favor de Salzedas, seja-nos permitido remeter para o nosso recente trabalho A organização de uma diocese: Lamego, da reconquista à restauração da dignidade episcopal. In SARAIVA, Anísio Miguel de Sousa; BRAGA, Alexandra (coord.) - Espaço, poder e memória: A Sé de Lamego em oito séculos de história (no prelo).
} 
pontifical lançando a benção, bem como a seguinte legenda: Sig. Menendi Lamecensis episcopi $^{30}$. O incêndio que fez desaparecer os documentos do cartório de Salzedas consumiu também este diploma, porém; nos fundos provenientes da Sé de Lamego, hoje conservados no Arquivo Nacional da Torre do Tombo, existe uma outra versão ${ }^{31}$, que não apresenta, contudo, qualquer vestígio de selagem, sendo provavelmente uma simples cópia; pelo que deste selo não conhecemos senão a descrição feita pelo grande erudito referido.

Verificamos, assim, que, a partir da década de 1140, começam a surgir casos dispersos e excepcionais de documentos autenticados com selos de prelados diocesanos, de que não chegou até nós nenhum exemplar, a não ser talvez o fragmento de um deles, em muito mau estado. É preciso esperar pelos anos 80 do século para encontrarmos dois selos episcopais intactos (ou quase); são posteriores ao falecimento de Afonso Henriques, mas foram, muito provavelmente (de certeza num dos casos), usados também antes da sua morte. Constam ambos de um diploma conservado nos fundos da Sé de Coimbra, outorgado em data desconhecida, mas que se pode situar com segurança entre Setembro de 1187 e Julho de 1188; por seu intermédio, definia-se o número de prebendas que devia ter o cabido dessa catedral $^{32}$. O diploma conserva ainda os três selos pendentes que recebeu. O primeiro, à esquerda, é o de D. Sancho I - não nos interessa de momento. O do meio pertence ao prelado de Coimbra, D. Martinho Gonçalves (1183-1191†), que já em 1183 validara dessa forma, juntamente com o arcebispo de Compostela, um outro diploma que nos chegou, porém, desprovido de $\operatorname{selos}^{33}$. O da direita é o do arcebispo de Braga D. Godinho (1176$1188 \dagger$ ), que, bispo desde 1176, possivelmente também teria já recorrido ao seu uso em anos anteriores, talvez mesmo durante o tempo em que ocupou a cátedra de Viseu, de 1171 até ser transferido para Braga, apesar de não termos notícias a esse respeito ${ }^{34}$. Estes dois selos episcopais merecem ser olhados com atenção, por serem os mais antigos que nos chegaram (figs. 2 e 3 ).

\footnotetext{
${ }^{30}$ RIBEIRO, J. P. - Observações historicas e criticas..., p. 143. COSTA, A. J. - Sigilografia, p. 564, refere a existência deste selo, sem, porém, indicar a fonte onde colheu os dados que indica.

${ }^{31}$ ANTT, Sé de Lamego, Doações, M. 1, nº 2, de Março de 1164.

${ }^{32}$ ANTT, Sé de Coimbra, $1^{\text {a }}$ inc., M. 8, no 39. Encontra-se reproduzido, se bem que com má qualidade, em COSTA, A. J. - Álbum de Paleografia ..., doc. 55. A sua data foi fixada por MORUJÃO, M. R. - A Sé de Coimbra..., p. 116, nota 197.

${ }_{33}$ ANTT, Sé de Coimbra, $1^{\text {a }}$ inc., M. 6, no 30. Cf. MORUJÃO, M. R. - A Sé de Coimbra ..., p. 639.

${ }^{34}$ Sobre D. Godinho, vid. CUNHA, M. C. - A chancelaria ..., p. 73-74.
} 


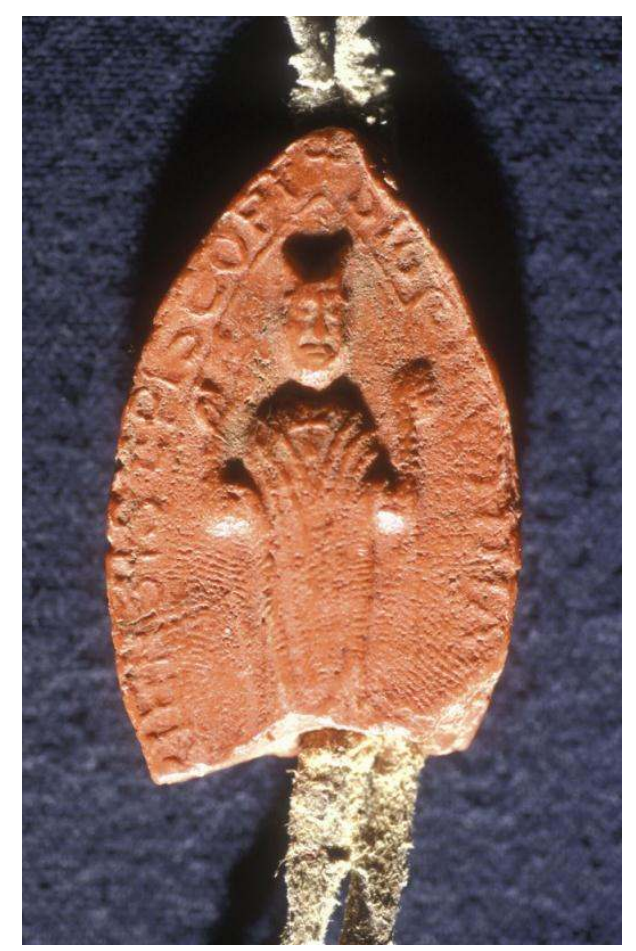

Fig. 2 - Selo de D. Martinho, bispo de Coimbra (ANTT, Sé de Coimbra, $1^{\mathrm{a}}$ inc., M. 8, no 39)

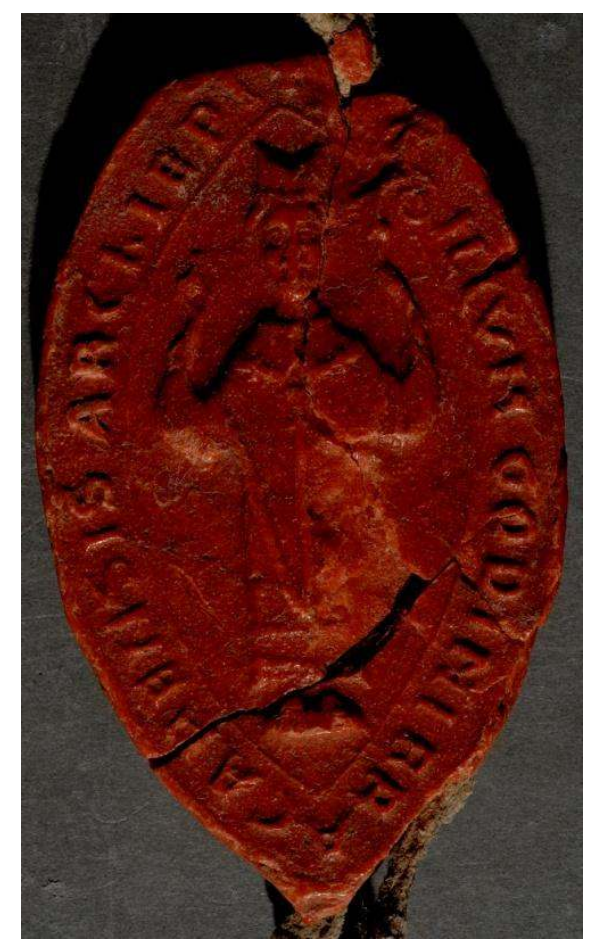

Fig. 3 - Selo de D. Godinho, arcebispo de Braga (ANTT, Sé de Coimbra, 1ª inc., M. 8, nº 39) 
Como se pode ver, ambos apresentam grandes semelhanças, e correspondem à mais usual tipologia sigilográfica episcopal da época. O campo é preenchido com uma representação do prelado, de pé, investido das suas insígnias pontificais, segurando o báculo na mão esquerda (pouco visível nas impressões de que dispomos) e erguendo a direita, em gesto de abençoar. Na cabeça, têm os dois uma mitra bicórnica, porque colocada de lado, como era uso então ${ }^{35}$. Na orla, surge a legenda identificadora dos sigilantes, que segue o modelo corrente, já referido em relação a D. Mendo de Lamego, explicitando tratar-se do selo de $\mathrm{N}$, bispo (ou arcebispo) de $\mathrm{X}$ ou $\mathrm{Y}^{36}$. É também digno de referência o facto de estes selos não terem sido gravados num bloco de cera arredondado na parte de trás, como habitualmente, mas antes sobre cera vertida num molde plano, o que resultou num reverso completamente liso, e numa espessura mínima (de $8 \mathrm{~mm}$ no caso do selo de D. Martinho, e de $6 \mathrm{~mm}$ apenas no de D. Godinho).

Com a mesma data crítica de [1187-88] surge-nos ainda a notícia de um outro selo episcopal de um bispo contemporâneo de D. Afonso Henriques, D. João, bispo de Viseu entre 1179 e $1192^{37}$. O selo desapareceu, mas as suspensões remanescentes atestam, ainda hoje, a sua existência.

Ficam-nos assim a faltar provas de utilização de selo pelo bispo de Évora, a única diocese ainda não mencionada de entre as que existiam ao tempo do rei fundador ou por ele foram restauradas. Luís Gonzaga de Lancastre e Távora, na sua fundamental obra O estudo da sigilografia medieval portuguesa, que continua a ser o mais importante reportório dos selos conservados em Portugal, refere duas impressões sigilares de D.

\footnotetext{
${ }^{35}$ Vid. BAUTIER, R.-H. - Apparition, diffusion..., p. 235 e MORUJÃO, M. R. - Imagens de selos..., p. 66-67.

${ }^{36}$ Quanto à legenda do selo de D. Martinho de Coimbra, vid. MORUJÃO, M. R. - A Sé de Coimbra.... p. 640, que avança mais na leitura do que TÁVORA, L. G. - O estudo da sigilografia ..., no ${ }^{\circ}$ 89, p. 145-146 (datando erradamente o diploma de 1186). Acerca da patente no selo de D. Godinho, arcebispo de Braga, veja-se este último autor, $\mathrm{n}^{\circ}$ 90, p. 146.

37 ANTT, Sé de Viseu, DP, M. 9, nº 29; vid. CUNHA, M. C.; SARAIVA, A. M.; MORUJÃO, M. R. Traditionalisme, régionalisme et innovation dans les chancelleries épiscopales portugaises au Moyen Âge. In KRESTEN, Otto; LACKNER, Franz (eds.) - Régionalisme et internationalisme: Problèmes de paléographie et de codicologie du Moyen Âge. Actes du XV Colloque du Comité International de Paléographie Latine (Vienne, 13-17 septembre 2005). Viena: Verlag der Österreichischen Akademie der Wissenschaften, 2008, p. 308.
} 
Soeiro, primeiro bispo da diocese eborense, datadas de 1180 e $1181^{38}$. Esta identificação está errada, porém: em 1180, já D. Soeiro tinha sido substituído na cátedra pelo seu sucessor D. Paio ${ }^{39}$, e os documentos em causa são, na realidade, da década de 20 do século XIII; os selos pertencem a D. Soeiro II, bispo de Évora nessa altura, e não ao seu antecessor e homónimo ${ }^{40}$. Falta uma análise exaustiva da documentação da Sé de Évora deste período para podermos verificar se existe algum vestígio da utilização do selo pelos seus bispos ainda no século XII.

De qualquer forma, os dados apurados, com base nos documentos que chegaram até nós, permitem concluir que os selos episcopais se difundiram gradualmente desde meados da década de 1140 no Portugal de Afonso Henriques. Eram usados ainda com grande parcimónia, apenas em documentos de especial solenidade. Foi preciso esperar pela viragem do século para passarem a ter uma utilização corrente e se tornarem o principal, e até único, modo de validação dos documentos outorgados pelos bispos portugueses, como sucedeu, por exemplo, logo a partir do início de Duzentos, na Sé de Coimbra $^{41}$. Será igualmente nessa época que os cabidos catedralícios, bem como os seus cónegos, a nível individual, os começarão a adoptar também ${ }^{42}$.

No que toca às ordens religiosas, tanto monásticas como militares, as informações com que contamos ainda são mais lacunares, quer devido à perda de numerosa documentação original, quer por falta de estudos que nos elucidem sobre tal matéria ${ }^{43}$. Os dados disponíveis apontam para que, como já afirmámos, as suas práticas

\footnotetext{
${ }^{38}$ O estudo da sigilografia..., $\mathrm{n}^{\circ} 84$ e 85, p. 143-144.

${ }^{39}$ Sobre estes bispos de Évora, vid. VILAR, H. V. - As dimensões de um poder..., p. 22-29.

${ }^{40}$ Assim conclui GOMES, S. A. - A chancelaria do mosteiro de S. Vicente de Fora de Lisboa nos séculos XII e XIII: subsídio para o seu conhecimento. In Summus Philologus necnon Verborum Imperator. Colectânea de estudos em homenagem ao académico de mérito, Professor Dr. José Pedro Machado no seu $90^{\circ}$ aniversário, Lisboa: Academia Portuguesa de História, 2004, p. 174, que indica a data exacta de um dos documentos em causa (ANTT, Mosteiro de S. Vicente de Fora, M. 2, $\mathrm{n}^{\circ} 20$ ) como 1224, o que corresponde ao episcopado de D. Soeiro II, que ocorreu entre 1206 e 1229 (cf. VILAR, H. V. - As dimensões de um poder..., p. 36).

${ }^{41}$ Cf. MORUJÃO, M. R. - A Sé de Coimbra ..., p. 676.

${ }^{42}$ Cf. MORUJÃO, M. R. - A Sé de Coimbra..., p. 657-665; SILVA, M. J. - Scriptores et notatores..., p. 125-127; CUNHA, M. C.; SARAIVA, A. M.; MORUJÃO, M. R. - Traditionalisme..., p. 303-304 e 308.

${ }^{43}$ Sobre o uso dos selos por estas instituições, vid. os exemplos apresentados por TÁVORA, L. G. - O estudo da sigilografia... e os trabalhos de Saul Gomes que citaremos nas notas seguintes.
} 
sigilográficas sejam um pouco mais tardias do que as episcopais, raramente anteriores a 1200; o que não deixa de nos intrigar, dado que, na maioria dos casos, se trata de instituições de origem exterior a Portugal que, noutras paragens, já recorriam à validação através dos selos durante a centúria de Undecentos. Assim sucede, por exemplo, com os Templários, que, no tempo de D. Teresa, se instalaram no condado; os seus documentos nacionais tardaram em ser dotados de selos, cujo uso era "ainda relativamente fugaz no último terço do século XII", de acordo com a breve abordagem às chancelarias das ordens militares portuguesas efectuada por Saul Gomes ${ }^{44}$, que não refere nenhum selo do Templo anterior ao século XIII.

Quanto às ordens monásticas, os estudos levados a cabo por este mesmo autor apontam para uma maior precocidade dos mosteiros de obediência cisterciense face aos das outras regras, mas mesmo neles só tardiamente surgem provas concretas e fidedignas da utilização do selo ${ }^{45}$. De facto, o primeiro documento cisterciense selado conhecido que não levanta suspeitas é de 1188; a impressão sigilar, perdida, pertencia ao abade de Maceiradão, tal como é do superior deste mesmo mosteiro da diocese de Viseu o primeiro selo que efectivamente chegou até nós, datado de $1220^{46}$. Há também notícias de um selo abacial undecentista em Alcobaça, mas só no século XIII é que contamos com testemunhos concludentes e seguros da utilização sigilar na principal casa cisterciense do reino ${ }^{47}$. O que é de admirar pois, como dissemos, os mosteiros portugueses tinham contacto com os dos restantes territórios, mormente com os franceses, onde as práticas sigilográficas datavam já de longas décadas, sendo bem conhecidos os selos de S. Bernardo de Claraval e as falsificações de que foram alvo e que conduziram o santo a mudar de matriz ${ }^{48}$.

\footnotetext{
44 GOMES, S. A. - Observações em torno da chancelaria da Ordem do Templo em Portugal. In FERNANDES, Isabel Cristina F. (coord.) - As Ordens Militares e as Ordens de Cavalaria entre o Ocidente e o Oriente. Actas do V Encontro sobre Ordens Militares, Palmela: Câmara Municipal / Gabinete de Estudos sobre a Ordem de Santiago, 2009, p. 130.

${ }^{45}$ Vid. a este respeito GOMES, S. A. - Sigillis abbatis et conventus muniatur - a sigilografia cisterciense medieval em Portugal. Signum. Revista da ABREM. S. Paulo. 9 (2007), p. 9-52; Imago \& auctoritas. Selos medievais da chancelaria de Santa Maria de Alcobaça, Coimbra: Palimage / Centro de História da Sociedade e da Cultura, 2008.

${ }^{46}$ GOMES, S. A. - Sigillis abbatis..., p. 24-25; Imago \& auctoritas..., p. 40.

${ }^{47}$ GOMES, S. A. - Imago \& auctoritas..., p. 40.

${ }^{48}$ A este caso alude GOMES, S. A. - Sigillis abbatis..., p. 14-16; Introdução à sigilografia ..., p. 67.
} 
Esta situação não difere muito da respeitante às instituições de cónegos regrantes de Santo Agostinho. Os dados que possuímos referem-se a Santa Cruz de Coimbra e a S. Vicente de Fora, as duas mais importantes casas regrantes portuguesas. As primeiras notícias comprovadas sobre selos crúzios não são anteriores aos inícios de Duzentos, como nos diz o aprofundado estudo levado a cabo sobre a chancelaria dessa canónica agostinha por Saul Gomes ${ }^{49}$; quanto a S. Vicente de Fora, o Marquês de Abrantes noticia um selo do mosteiro de $1189^{50}$, redondo, com um corvo no campo, primeira representação conhecida deste elemento da simbologia vicentina, que constará, igualmente, das matrizes sigilares posteriores do mosteiro ${ }^{51}$. A selagem, no entanto, também só se virá a tornar uma prática comum dos regrantes lisboetas a partir do século XIII, em especial da década de $1230^{52}$.

Relativamente aos mosteiros beneditinos não dispomos de quaisquer elementos, nem mesmo sobre Lorvão, cuja chancelaria já foi objecto de um estudo parcelar, o qual, no entanto, não incide sobre os processos de validação ${ }^{53}$. Nenhum selo undecentista de proveniência beneditina está patente no corpus compilado pelo Marquês de Abrantes; pelo que podemos concluir que, à luz dos actuais conhecimentos sobre a matéria, as práticas sigilográficas nos meios monásticos portugueses foram muito raras, se não mesmo inexistentes, durante o século XII, só se desenvolvendo e ganhando protagonismo durante a centúria seguinte.

Resta-nos abordar, para concluir, a problemática do uso do selo pela chancelaria de D. Afonso Henriques. Esta é uma questão envolta em dúvidas e discussões, como tantas outras relativas ao nosso primeiro rei, não se podendo ter a certeza que o selo tenha sido de facto sido um dos processos validatórios utilizados pela sua chancelaria. É certo que,

\footnotetext{
${ }^{49}$ In limine..., p. 843-913.

${ }^{50}$ TÁVORA, L. G. - O estudo da sigilografia ..., nº 93, p. 143.

${ }^{51}$ Algumas reproduções das impressões sigilares obtidas por meio dessas matrizes podem ser vistas em TÁVORA, L. G. - O estudo da sigilografia ..., no 154 (p. 174), 193 (p. 191-192), 200 (p. 194), 214 (p. 200-201), 234 (p. 209), 433 (p. 300-301), 434 (p. 301).

${ }^{52}$ GOMES, S. A. - A chancelaria do mosteiro de S. Vicente de Fora..., p. 190.

${ }^{53}$ COELHO, Maria Helena da Cruz - Análise diplomática da produção documental do scriptorium de Lorvão (séculos X-XII). In Estudos em homenagem ao Prof. Doutor José Marques. Vol. 3. Porto: Faculdade de Letras da Universidade, 2006, p. 387-405.
} 
desde sempre, se tem feito referência a diplomas afonsinos autenticados por essa via; no entanto, trata-se, em todos os casos que foram sujeitos ao crivo de uma crítica aprofundada, de documentos que nos deixam dúvidas, quando não de reconhecidas falsificações ou de cópias posteriores que têm passado por originais ${ }^{54}$.

Na sua História Genealógica da Casa Real Portuguesa, o erudito setecentista D. António Caetano de Sousa publica uma estampa com um desenho do selo de cera pendente de D. Afonso Henriques aposto numa doação a Santa Cruz datada de $1133^{55}$, estampa essa que tem, desde então, sido largamente reproduzida, até mesmo pelo historiador que mais recente e aprofundadamente se dedicou ao estudo da chancelaria régia portuguesa, Avelino de Jesus da $\operatorname{Costa}^{56}$ (fig. 4). Sabe-se hoje, todavia, que o documento em causa, ainda existente, conta, afinal, menos dez anos; que não se trata de um original, mas de cópia elaborada no século XIII; e que ostenta um selo régio, sem dúvida, mas pertencente, decerto, a D. Afonso II $^{57}$.

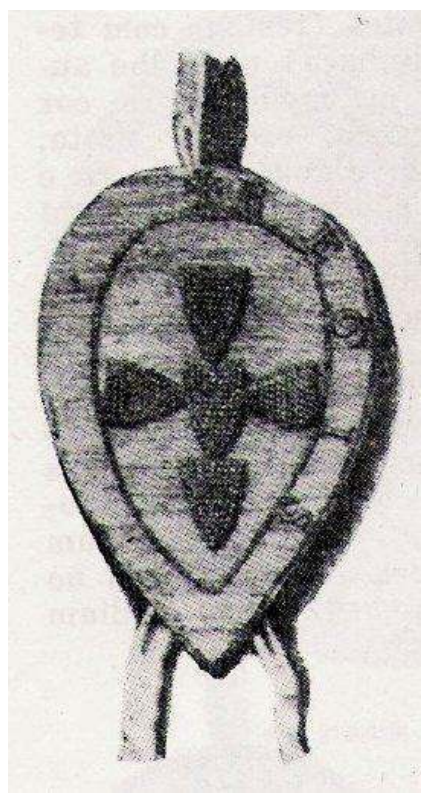

Fig. 4 - Desenho do selo de D. Afonso Henriques, segundo António Caetano de Sousa (apud COSTA, A. J. - "La chancellerie royale...", planche V, n 1)

${ }^{54}$ Cf. S. A. GOMES - Introdução à sigilografia ..., p. 88-90.

55 SOUSA, António Caetano de - História Genealógica da Casa Real Portuguesa. Tomo 4, livro 5. Lisboa/Porto: QuidNovi / Público / Academia Portuguesa da História, 2007 (reprodução da ed. de 1947, revista por M. Lopes de Almeida e César Pegado), p. 19 e estampa 1.

${ }^{56}$ COSTA, A. J. - La chancellerie royale...", planche V, n ${ }^{\circ} 1$.

${ }^{57}$ GOMES, S. A. - Introdução à sigilografia ..., p. 90. 
Um outro documento do rei fundador que se encontra selado é a carta pela qual doa o couto do mosteiro de Alcobaça a S. Bernardo, em $1153^{58}$. O diploma apresenta, de facto, um selo pendente, muito delido, mas que parece ter o formato de dupla ogiva, e não o feitio de escudo ou amendoado típico dos primeiros selos régios portugueses. Além disso, a dobra do pergaminho onde o selo foi aplicado constitui um acrescento; já João Pedro Ribeiro era de opinião de que este documento tinha sido selado posteriormente, com um selo que não era o do primeiro rei ${ }^{59}$.

Parecia poder servir como prova do uso do selo por Afonso Henriques um outro diploma concedido pelo monarca a Alcobaça, em Maio de 1157, que ainda conserva a suspensão sigilar. Recentemente, porém, o seu carácter de original foi posto em causa, dadas as diferentes características internas e externas que apresenta em relação a outros actos outorgados pelo mesmo rei e, sobretudo, por apresentar uma corroboração de D. Sancho I que aponta para que se trate de uma renovação ou confirmação por este do documento de seu pai, e, portanto, selado por ele e não por Afonso Henriques ${ }^{60}$.

Referimos atrás a carta do bispo D. Gilberto de 1159 como podendo ter sido autenticada com a matriz sigilar do primeiro rei; mas nada o garante, e vimos como era provável que o selo aposto fosse o do próprio bispo lisboeta, que é, afinal, o autor do diploma. Resta-nos, assim, como prova do uso do selo por Afonso Henriques, a mencionada e tão contestada carta de liberdade concedida aos crúzios pelo bispo de Coimbra, onde sabemos ter sido colocado o selo régio, mesmo que em data posterior àquela em que o documento foi lavrado, ou seja, Março de 1162. Como dissemos, é muito difícil ver no único fragmento de cera remanescente uma imagem coerente, e nem o formato que o selo teria se consegue adivinhar com segurança. Mas, se foi, como tudo indica, selado durante o episcopado de D. Miguel, que se manteve à frente da diocese de Coimbra até 1176, o selo régio que recebeu teve de ser, forçosamente, o de D. Afonso Henriques.

\footnotetext{
58 ANTT, Mosteiro de Alcobaça, DR, M. 1, $\mathrm{n}^{\circ}$ 1; reproduzido por GOMES, S. A. - Imago \& Auctoritas..., p. 117.

${ }^{59}$ RIBEIRO, João Pedro - Dissertações chronologicas e criticas sobre a historia e jurisprudencia ecclesiastica e civil de Portugal. Tomo 1. Lisboa: Tipografia da Academia Real das Ciências, 1810, p. 54-82; vid. também GOMES, S. A. - Introdução à sigilografia ..., p. 89.

${ }^{60}$ GOMES, S. A. - Introdução à sigilografia ..., p. 89.
} 
Por isso, este documento, tão polémico, parece-nos poder constituir a melhor, ainda que frágil, prova de que o nosso primeiro rei, à semelhança de seu primo Afonso VII de Leão e Castela (1135-1157) e do sucessor deste, Fernando II (1157-1188), também seu contemporâneo, usou, de facto, um selo pendente ${ }^{61}$.

E que aspecto teria esse selo? Não nos parece que existam razões para duvidar de que se trataria de um selo de tipo heráldico, apresentando as armas do monarca ${ }^{62}$, que se vieram a transformar nas armas do próprio reino e para sempre permaneceram como característica específica e diferenciadora da sigilografia régia portuguesa.

Efectivamente, enquanto a generalidade dos monarcas da Idade Média se fez representar nos seus selos em majestade, ou seja, sentados no trono e munidos dos atributos próprios da sua autoridade, com os reis portugueses tal nunca sucedeu ${ }^{63}$, tendo a primazia sido dada, sempre, nas matrizes sigilares, às armas portuguesas. De D. Afonso III a D. Fernando, houve também selos equestres, a outra tipologia de selos régios mais usada pelos soberanos europeus, mas nunca os motivos heráldicos foram deixados de lado, constando do reverso das selagens ${ }^{64}$. Esta originalidade portuguesa não nos parece ser devida ao facto de se tratar de uma pequena monarquia em fase de expansão territorial, como já foi aventado; opina Saul Gomes que a figuração heráldica "favorece a noção de um poder real que se visualiza pelo símbolo abstracto e geométrico", em lugar de uma "imagem personalizada dos monarcas", e que isso corresponderia a uma

\footnotetext{
${ }^{61}$ Sobre os selos destes soberanos, vid. RUIZ, Teófilo F. - L’image du pouvoir à travers les sceaux de la monarchie castillane. In Génesis medieval del Estado moderno: Castilla y Navarra (1250-1370). Valladolid: Ambito Ed., 1987, p. 217-227.

${ }^{62}$ Para tal aponta não apenas a tradição, mas também o facto de dois filhos do monarca cujos selos se conhecem, D. Sancho I e D. Matilde, condessa da Flandres, terem usado precisamente matrizes sigilares heráldicas e em forma de escudo, com a representação das quinas carregadas de besantes, que foram decerto herdadas de seu pai. Sobre o selo de Matilde, vid. BEDOS-REZAK, Brigitte - Women, seals and power in medieval France, 1150-1350. In Form and Order in Medieval France. Aldershot: Variorum, 1993, p. 69.

${ }^{63}$ Terá havido, eventualmente, uma excepção com D. Sancho I, cujo selo, apresentando o monarca de pé, munido dos seus atributos régios, foi desenhado em cópias de documentos seus muito posteriores (uma da segunda metade do século XIII, conservada em ANTT, Gavetas, Gav. 15, M. 10, nº 14, e outra do século XIV, que se encontra em ANTT, Livro das Doações de Afonso III, fl. 13v; podem ver-se as reproduções desses desenhos em BRANCO, Maria João - D. Sancho I. O filho do Fundador. Rio de Mouro: Círculo de Leitores, 2006, figs. 3a e 3b). O seu reverso, porém, garante a descrição patente numa das cópias, tinha gravado o escudo de armas do rei, semelhante aos patentes nos selos que chegaram até nós, de dupla-face e forma amendoada ou de escudo, com as armas do monarca representadas em ambos os lados.

${ }^{64}$ Vid. síntese apresentada sobre a sigilografia régia portuguesa por GOMES, S. A. - Introdução à sigilografia..., p. 90-95, que reproduz vários selos régios equestres.
} 
"opção de fundo ideológico"65. Perguntamos nós, diante desta singularidade, se ela não será devida à importância que o próprio escudo de armas de Afonso Henriques assumiu desde logo, no imaginário da época, como emblema do poder régio conquistado pelo esforço e talento de guerreiro do infante, residindo aí a matriz identitária do símbolo nacional.

José Mattoso, nos mais recentes trabalhos que dedicou ao rei fundador, nomeadamente na sua biografia, valoriza o passo da Crónica Geral de Espanha de 1344 que "conta a estoria que os seus que o alçarom por rey" antes da batalha de Ourique ${ }^{66}$, a partir da qual o infante passou, efectivamente, a intitular-se rex. Coloca o eminente historiador a hipótese de que o termo "alçar" pudesse designar a cerimónia de aclamação do rei de pé sobre o seu escudo, como se fazia em Navarra, pela mesma altura ${ }^{67}$. Mattoso associa este facto à sugestão, baseada em representações quinhentistas e seiscentistas ${ }^{68}$, e resultante da polémica travada a partir do século XIX em torno do milagre de Ourique e da criação das armas reais como agradecimento pela ajuda prestada por Cristo a Afonso Henriques na batalha, de que as armas reais portuguesas teriam como base uma estilização do carbúnculo, ou seja, a estrutura metálica que reforçava o escudo que o infante usava como arma de defesa ${ }^{69}$. De acordo com esta interpretação, os besantes, em lugar de simbolizarem os dinheiros pagos a Judas, e os escudetes, em vez de representarem os cinco reis mouros derrotados em Ourique, corresponderiam, antes, a essas ferragens do escudo do monarca. Os mais recentes estudos dedicados à heráldica régia, porém, mostram como faltam fundamentos e provas documentais a uma tal explicação das armas de Afonso Henriques. João Paulo de Abreu e Lima recolocou a questão no seu contexto ${ }^{70}$, procurando as mais antigas fontes que permitam estudar essas armas, chegando à conclusão de que os primeiros textos que tentam explicar as

\footnotetext{
${ }^{65}$ GOMES, S. A. - Introdução à sigilografia ..., p. 94.

${ }^{66}$ MATTOSO, José - D. Afonso Henriques, Rio de Mouro: Círculo de Leitores, 2006, p. 120.

${ }^{67}$ MARQUES, Maria Alegria; SOALHEIRO, João - A corte dos primeiros reis de Portugal. Afonso Henriques. Sancho I. Afonso II. Gijón: Trea, 2009, p. 33-40, retomam e desenvolvem esta mesma ideia. Note-se que também em Navarra os selos reais apresentavam as armas dos monarcas; no entanto, só surgiam no reverso, e dentro de um escudo que ocupava o campo de um selo redondo, o que é bem diferente do que se passa em Portugal; cf. RUIZ, Teófilo F. - L’image du pouvoir...

${ }^{68}$ Vid. LIMA, João Paulo de Abreu e - Armas de Portugal: origem, evolução, significado. Lisboa: Inapa, 1998, p. 19.

69 Assim defenderam, por exemplo, CORDEIRO, Luciano - A condessa Mahaut, Lisboa: A Liberal, 1899, p. 95-115 e por TÁVORA, L. G. - Introdução ao estudo da heráldica, Lisboa: Instituto de Cultura e Língua Portuguesa, 1992, p. 24.

${ }^{70}$ LIMA, J. P. - Armas de Portugal ..., p. 3-23.
} 
suas origens as ligam, com toda a clareza, à batalha de Ourique e à ajuda que o infante acreditava ter recebido de Cristo crucificado ${ }^{71}$.

Para o propósito que nos anima, o significado real das armas de Afonso Henriques questão "delicada e difícil de resolver",72 - não é o mais importante. Interessa-nos, sim, que o selo do primeiro rei de Portugal terá recorrido à representação das suas armas. As quinas, dispostas em forma de cruz, terão passado a figurar, depois de Ourique, no escudo do rei, que foi venerado como relíquia no mosteiro de Santa Cruz de Coimbra, pendurado por cima do seu túmulo, pelo menos até ao século $\mathrm{XVI}^{73}$. Reza a tradição que se soltava da parede, sem que ninguém lhe tocasse, quando algum monarca português falecia, lenda que mais evidencia o seu valor singular ${ }^{74}$.

O escudo do rei, símbolo do seu valor guerreiro, surge assim associado, indissoluvelmente, à génese da monarquia portuguesa. Afonso Henriques ganhara o trono pelas armas; fora, pela sua tenacidade e pelo seu valor como combatente, muito provavelmente alçado rei pelos seus companheiros antes ainda de ser reconhecido como tal pelos outros monarcas e pelo papado. As suas armas tornaram-se o "sinal visível do pacto sagrado que justificava a dinastia e proclamava simbolicamente a independência do reino" 75 , que todos os seus sucessores fizeram questão de usar, actualizando-as e acrescentando-as embora. Essas mesmas armas passaram a figurar nos selos dos reis portugueses, no que é um caso singular dentro da panorâmica sigilográfica dos restantes reinos europeus. Mesmo não nos tendo legado nenhum dos seus selos, D. Afonso Henriques deixou, pois, às práticas sigilares régias de Portugal a sua principal matriz: o seu próprio escudo, transformado no símbolo maior da autoridade dos monarcas e do reino que ele fizera nascer.

\footnotetext{
${ }^{71}$ Essas fontes são a Crónica Geral de Espanha de 1344. Ed. crítica de L. F. Lindley Cintra. Tomo 4. Lisboa: Academia Portuguesa de História, 1990, p. 224-225; e Crónica de Portugal de 1419. Edição crítica com introdução e notas de Adelino de Almeida Calado. Aveiro : Universidade, 1998.

${ }^{72}$ Assim o diz SEIXAS, Miguel Metelo de - El simbolismo del territorio en la heráldica regia portuguesa. En torno a las armas del Reino Unido de Portugal, Brasil y Algarves. Emblemata. Zaragoza. 16 (2010), p. 289.

${ }^{73}$ Como informa MATTOSO, J. - D. Afonso Henriques, p. 121; SOUSA, A. C. - História genealógica ..., vol. 1, p. 35, afirma, porém, que esse escudo ainda se conservava no mosteiro crúzio no século XVIII.

${ }^{74}$ Essa lenda conserva-se no conhecido Livro de Arautos, estudado e publicado por NASCIMENTO, Aires Augusto do - Livro de Arautos = De ministerio armorum. Estudo codicológico, histórico, literário, linguístico. Lisboa: [s.n.], 1977, p. 251.

${ }^{75}$ SEIXAS, M. M.- El simbolismo..., p. 288-289.
} 


\section{Fontes manuscritas:}

\section{Arquivo Nacional da Torre do Tombo (ANTT)}

Gavetas, Gav. 7, M. 3, nº 8; Gav. 15, M. 10, nº 14.

Livro das Doações de Afonso III, fl. 13v.

Mosteiro de Alcobaça, DR, M. 1, nº 1 .

Mosteiro de Santa Cruz, DP, M. 5, $\mathrm{n}^{\circ} 18$.

Mosteiro de S. Vicente de Fora, M. 2, n $^{\circ} 20$.

Sé de Coimbra, $1^{\text {a }}$ inc., M. 6, nº 30; M. 8, nº 39.

Sé de Lamego, Doações, M. 1, nº 2.

Sé de Viseu, DP, M. 9, nº 29.

\section{Fontes impressas:}

Censual do Cabido da Sé do Porto: códice membranáceo existente na Biblioteca do Porto. Ed. João Grave. Porto: Imprensa Portuguesa, 1924.

Crónica Geral de Espanha de 1344. Ed. crítica de L. F. Lindley Cintra. Tomo 4. Lisboa: Academia Portuguesa de História, 1990, p. 224-225.

Crónica de Portugal de 1419. Edição crítica com introdução e notas de Adelino de Almeida Calado. Aveiro: Universidade, 1998 


\section{Bibliografia:}

AZEVEDO, Rui de - Documentos falsos de Santa Cruz de Coimbra (séculos XII e XIII), Lisboa: José Fernandes Júnior, 1935.

BAUTIER, Robert-Henri - Apparition, diffusion et évolution typologique du sceau épiscopal au Moyen Âge. In HAIDACHER, Christoph; KÖFLER, Werner (eds.) - Die Diplomatik der Bischofsurkunde vor 1250. La Diplomatique épiscopale avant 1250. Innsbruck: Tiroler Landesarchiv, 1995, p. 225-241.

BAUTIER, Robert-Henri - Le cheminement du sceau et de la bulle des origines mésopotamiennes au XIII ${ }^{\mathrm{e}}$ siècle occidental. In BAUTIER, Robert-Henri - Chartes, sceaux et chancelleries. Études de Diplomatique et de Sigillographie médiévales. Vol. 1. Paris: École des Chartes, 1990, p. 123-166.

BEDOS-REZAK, Brigitte - Women, seals and power in medieval France, 1150-1350. In Form and Order in Medieval France. Aldershot: Variorum, 1993, p. 61-82.

BRANCO, Maria João - D. Sancho I. O filho do Fundador. Rio de Mouro: Círculo de Leitores, 2006.

BRANCO, Maria João Violante - Reis, bispos e cabidos: a diocese de Lisboa durante o primeiro século da sua restauração. Lusitania Sacra, Lisboa. 10 (1998), p. 55-94.

COELHO, Maria Helena da Cruz - Análise diplomática da produção documental do scriptorium de Lorvão (séculos X-XII). In Estudos em homenagem ao Prof. Doutor José Marques. Vol. 3. Porto: Faculdade de Letras da Universidade, 2006, p. 387-405.

CORDEIRO, Luciano - A condessa Mahaut, Lisboa: A Liberal, 1899. 
COSTA, Avelino de Jesus da - Álbum de Paleografia e Diplomática Portuguesas. Estampas. 6a edição. Coimbra: Faculdade de Letras / Instituto de Paleografia e Diplomática, 1997.

COSTA, Avelino de Jesus da - La chancellerie royale portugaise jusqu'au milieu du XIII ${ }^{\mathrm{e}}$ siècle. In COSTA, Avelino de Jesus da - Estudos de Cronologia, Diplomática, Paleografia e Histórico-Linguísticos. Porto: Sociedade Portuguesa de Estudos Medievais, p. 137-166.

COSTA, Avelino de Jesus da - D. João Peculiar, co-fundador do mosteiro de Santa Cruz de Coimbra, bispo do Porto e arcebispo de Braga. In Santa Cruz de Coimbra do século XI ao século XX. Estudos no IX centenário do nascimento de S. Teotónio. Coimbra: [s.n.], 1984, p. 59-83.

COSTA, Avelino de Jesus da - Sigilografia. In SERRÃO, Joel (dir.) - Dicionário de História de Portugal. Vol. 5. Porto: Figueirinhas, [s.d.], p. 562-568.

CUNHA, Maria Cristina Almeida e - A chancelaria arquiepiscopal de Braga (1071-1244). Noia: Toxosouto, 2005.

CUNHA, Maria Cristina Almeida e; SARAIVA, A. Anísio Miguel de Sousa; MORUJÃO, Maria do Rosário Barbosa - Traditionalisme, régionalisme et innovation dans les chancelleries épiscopales portugaises au Moyen Âge. In KRESTEN, Otto; LACKNER, Franz (eds.) - Régionalisme et internationalisme: Problèmes de paléographie et de codicologie du Moyen Âge. Actes du XV Colloque du Comité International de Paléographie Latine (Vienne, 13-17 septembre 2005). Viena: Verlag der Österreichischen Akademie der Wissenschaften, 2008, p. p. 299-316.

GOMES, Saul António - A chancelaria do mosteiro de S. Vicente de Fora de Lisboa nos séculos XII e XIII: subsídio para o seu conhecimento. In Summus Philologus necnon Verborum Imperator. Colectânea de estudos em homenagem ao académico de mérito, Professor Dr. José Pedro Machado no seu $90^{\circ}$ aniversário, Lisboa: Academia Portuguesa de História, 2004, p. 163-213. 
GOMES, Saul António - Imago \& auctoritas. Selos medievais da chancelaria de Santa Maria de Alcobaça, Coimbra: Palimage / Centro de História da Sociedade e da Cultura, 2008.

GOMES, Saul António - In limine conscriptionis. Documentos, chancelaria e cultura no mosteiro de Santa Cruz de Coimbra: séculos XII a XIV. Viseu: Palimage, 2007.

GOMES, Saul António - Introdução à sigilografia portuguesa. Guia de estudo. Coimbra: Faculdade de Letras, 2008.

GOMES, Saul António - Observações em torno da chancelaria da Ordem do Templo em Portugal. In FERNANDES, Isabel Cristina F. (coord.) - As Ordens Militares e as Ordens de Cavalaria entre o Ocidente e o Oriente. Actas do V Encontro sobre Ordens Militares, Palmela: Câmara Municipal / Gabinete de Estudos sobre a Ordem de Santiago, 2009, p. 121-139.

GOMES, Saul António - Sigillis abbatis et conventus muniatur - a sigilografia cisterciense medieval em Portugal. Signum. Revista da ABREM. S. Paulo. 9 (2007), p. $9-52$.

GUERRA, António Joaquim Ribeiro - Os diplomas privados em Portugal dos séculos IX a XII. Gestos e atitudes de rotina dos seus autores materiais. Lisboa: Centro de História da Universidade, 2003.

HARVEY, P. D. A.; MCGUINESS, Andrew - A guide to British medieval seals. Londres: British Library / Public Record Office, 1996.

LIMA, João Paulo de Abreu e - Armas de Portugal: origem, evolução, significado. Lisboa: Inapa, 1998.

MARQUES, José - A influência das bulas papais na documentação medieval portuguesa. Revista da Faculdade de Letras. História. Porto, 13 (1996), p. 25-62. 
MARQUES, Maria Alegria F. - A introdução da Ordem de Cister em Portugal. In MARQUES, Maria Alegria F. - Estudos sobre a Ordem de Cister em Portugal, Lisboa: Colibri, 1998, p. 29-73.

MARQUES, Maria Alegria; SOALHEIRO, João - A corte dos primeiros reis de Portugal. Afonso Henriques. Sancho I. Afonso II. Gijón: Trea, 2009.

MARTINS, Armando Alberto - O mosteiro de Santa Cruz de Coimbra na Idade Média, Lisboa: Centro de História da Universidade, 2003.

MATTOSO, José - Cluny, crúzios e cistercienses na formação de Portugal. In MATTOSO, José - Portugal medieval: novas interpretações. Rio de Mouro: Círculo de Leitores, 2002, p. 79-93.

MATTOSO, José - D. Afonso Henriques, Rio de Mouro: Círculo de Leitores, 2006.

MORUJÃO, Maria do Rosário Barbosa - Imagens de selos. Anotações de sigilografia pontifícia e episcopal. In Colecção Esfragística da Faculdade de Letras da Universidade de Coimbra. Catálogo da Exposição, Coimbra: Reitoria da Universidade, 2003, p. 61-70.

MORUJÃO, Maria do Rosário Barbosa - A organização de uma diocese: Lamego, da reconquista à restauração da dignidade episcopal. In SARAIVA, Anísio Miguel de Sousa; BRAGA, Alexandra (coord.) - Espaço, poder e memória: A Sé de Lamego em oito séculos de história (no prelo).

MORUJÃO, Maria do Rosário Barbosa - A Sé de Coimbra: a instituição e a chancelaria (1080-1318). Lisboa: FCG/FCT, 2010.

MORUJÃO, Maria do Rosário Barbosa - The seals from the fund of the Coimbra See Chapter at the Torre do Tombo National Archive. In Actas do Seminário Internacional "Preserving documents - science and restoration" (em vias de publicação on-line) 
NASCIMENTO, Aires Augusto do - Livro de Arautos $=$ De ministerio armorum. Estudo codicológico, histórico, literário, linguístico. Lisboa: [s.n.], 1977.

NOGUEIRA, Bernardo de Sá - Tabelionado e instrumento público em Portugal. Génese e implantação (1212-1279). Lisboa: Imprensa Nacional Casa da Moeda, 2008.

PASTOUREAU, Michel - Les sceaux. Turnhout: Brepols, 1981.

RIBEIRO, João Pedro - Dissertações chronologicas e criticas sobre a historia e jurisprudencia ecclesiastica e civil de Portugal. Tomo 1. Lisboa: Tipografia da Academia Real das Ciências, 1810.

RIBEIRO, João Pedro - Observações historicas e criticas para servirem de memorias ao systema da diplomatica portugueza, Lisboa: Tipografia da Academia Real das Ciências, 1798.

RIESCO TERRERO, Angel - El sello episcopal hasta el Renacimiento. Valoración jurídico-diplomática y artística del mismo. In Actas del XV Congreso Internacional de las Ciencias Genealógica y Heráldica. Madrid, 19-25 septiembre 1982. Tomo 3. Madrid: Instituto Salazar y Castro, 1983, p. 365-389.

RUIZ, Teófilo F. - L’image du pouvoir à travers les sceaux de la monarchie castillane. In Génesis medieval del Estado moderno: Castilla y Navarra (1250-1370). Valladolid: Ambito Ed., 1987, p. 217-227.

SANZ FUENTES, Maria Josefa - La recuperación de tipos sigilográficos y modos de aposición a traves de las formulas documentales. In Actas del Primer Coloquio de Sigilografía (Madrid, 2 al 4 de abril de 1987), Madrid: Direccion de los Archivos Estatales, 1990, p. 145-153.

SEIXAS, Miguel Metelo de - El simbolismo del territorio en la heráldica regia portuguesa. En torno a las armas del Reino Unido de Portugal, Brasil y Algarves. Emblemata. Zaragoza. 16 (2010), p. 285-329. 
SILVA, Maria João Oliveira e - Scriptores et notatores. A produção documental da Sé do Porto (1113-1247). Porto: Fio da Palavra, 2008.

SOUSA, António Caetano de - História Genealógica da Casa Real Portuguesa. Tomo 4, livro 5. Lisboa/Porto: QuidNovi / Público / Academia Portuguesa da História, 2007 (reprodução da ed. de 1947, revista por M. Lopes de Almeida e César Pegado).

TÁVORA, Luís Gonzaga de Lancastre e - O estudo da sigilografia medieval portuguesa. Lisboa: Instituto de Cultura e Língua Portuguesa, 1983.

TÁVVORA, Luís Gonzaga de Lancastre e - Introdução ao estudo da heráldica, Lisboa: Instituto de Cultura e Língua Portuguesa, 1992.

TORRE RODRÍGUEZ, José Ignacio de la - Evolução histórica de Cister no Vale do Douro. In DIAS, Geraldo Coelho; DUARTE, Luís Miguel (coord.) - Cister no Vale do Douro. Porto: Edições Afrontamento, 1999, p. 69-116.

VENTURA, Leontina - O elemento franco na Coimbra do século XII: a família dos Rabaldes. Revista Portuguesa de História. Coimbra. 36: 1 (2002-2003), p. 89-114.

VILAR, Hermínia Vasconcelos - As dimensões de um poder. A diocese de Évora na Idade Média. Lisboa: Estampa, 1999. 


\section{COMO CITAR ESTE ARTIGO}

\section{Referência electrónica:}

MORUJÃO, Maria do Rosário Barbosa - “A sigilografia portuguesa em tempos de Afonso Henriques”. Medievalista [Em linha]. Nº11, (Janeiro - Junho 2012). [Consultado dd.mm.aaaa]. Disponível em

http://www2.fcsh.unl.pt/iem/medievalista/MEDIEVALISTA11\morujao1103.html. ISSN 1646-740X.

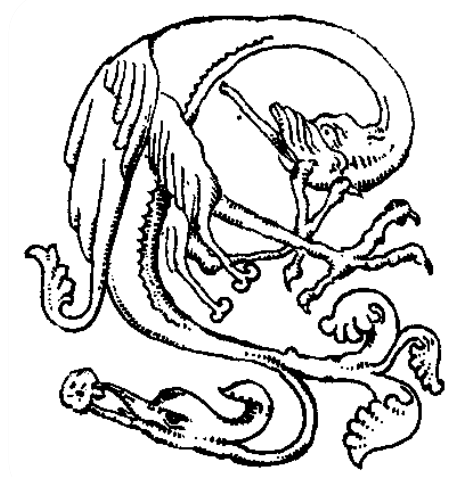

